\title{
EDITORIAL
}

\section{Fetal Biometry is a Prerequisite Part of Modern Antenatal Care}

\author{
Azen Salim
}

Accurate gestational-age estimation, preferably by ultrasound measurement of fetal crown-rump length (CRL) before 14 weeks' gestation, is an important component of high-quality antenatal care ${ }^{1-3}$ Gestational age determination during the first trimester has a minimal deviation.

The most precise way to estimate gestational age is by measuring CRL between $8^{+0}$ and $14^{+0}$ weeks gestation. It is associated with a 95\% prediction interval of 2.7 days. ${ }^{4,5}$ The impact of this finding is very significant in deciding whether the gestation is preterm or term. Unnecessary complications which occur in preterm babies could be avoided, and intensive care observation of the newborn will be minimised. Accurate dating of gestational age also supports us for the preparation of a fetus whenever has to be delivered due to unexpected condition e.g. premature preterm rupture of the amniotic membrane.

In case of fetal death, long bone measurements will inform us when the fetus died. It is crucial, especially in monochorionic diamniotic twins pregnancy. Twin to twin transfusion syndrome with one co-twin death has a high risk of complication to the living co-twin. It depends on when such a tragedy occurs. ${ }^{6}$ As we know, serious complications might influence the living co-twin.

Monitoring fetal growth and development longitudinally at second and third trimester as a follow up antenatal care is an essential integrated examination.7,8 Following the growth curve, any deviation will be identified. The deviation might be smaller or larger the normal curve. Tracing the growth curve of fetuses gives us a valuable information about its well-being. Any jeopardy of the fetuses can be detected, any interventions if needed can be planned thoroughly ${ }^{9}$

The measurement of each organ of the fetus can be plotted to its gestational age normal distribution curve or compared to each gestational age Z score. Deviation from its normal distribution curve or Z score may be identified, e.g. short limb, microcephaly, ventriculomegaly. ${ }^{10}$ By collecting information from such fetuses, a differential diagnosis could be made, e.g. skeletal dysplasia, short limb syndrome. Measurements information will guide us to the specific diagnosis.

Thus, uniform and standardised measurement and protocol have to be created to achieve optimal results. Training and operator standardisation performance would be a success if right centre and trainer were available. Training and certification programs to achieve a favourable result performing fetal biometry is a prerequisite. ${ }^{11,12}$

\section{References}

1. Wisser J, Dirschedl P, Krone S. Estimation of gestational age by transvaginal sonographic measurement of greatest embryonic length in dated human embryos. Ultrasound Obstet Gynecol 1994; 4: 457-62.

2. Snijders RJM, Nicolaides KH. Fetal biometry at 14-40 weeks' gestation. Ultrasound Obstet Gynecol 1994; 4: $34-48$.

3. Papageorghiou AT, Kemp B, Stones W, Ohuma EO, et al. Ultrasound-based gestational-age estimation in late pregnancy. Ultrasound Obstet Gynecol 2016; 48: 719-26.

4. Papageorghiou AT, Kennedy SH, Salomon LJ, Ohuma EO, Cheikh Ismail L, Barros FC, et al. International Fetal and Newborn Growth Consortium for the $21^{\text {st }}$ Century (INTERGROWTH-21 st).

5. Robinson HP. Sonar measurement of fetal crown-rump length as means of assessing maturity in first trimester of pregnancy. BMJ 1973;4:28-31.

6. Bajoria R, Wee LY, Anwar S, Ward S. Outcome of twin pregnancies complicated by single intrauterine death in relation to vascular anatomy of the monochorionic placenta. Hum Reprod 1999; 14: 2124 -30.

7. Owen P, Donnet ML, Ogston SA, Christie AD, Howie PW, Patel NB. Standards for ultrasound fetal growth velocity. BJOG, 1996; 103: 60-9.

8. Campbell S, Thoms A. Ultrasound measurement of the fetal head to abdomen circumference ratio in the assessment of growth retardation. BJOG, 1977; 84: 165-74.

9. Stirnemann J, Villar J, Salomon LJ, Ohuma E, Ruyan P, et al. International estimated fetal weight standards of the INTERGROWTH-21st Project. Ultrasound Obstet Gynecol 2017; 49: 478-86.

10. Chervenak FA, Jeanty P, Cantraine F, Chitkara U, Venus I, Berkowitz RL, et al. The diagnosis of fetal microcephaly. Am J Obstet Gynecol 1984; 149: 512-51.

11. AIUM. AIUM Practice Guideline for the performance of an antepartum obstetric ultrasound examination. J Ultrasound Med 2003; 22: 1116-25.

12. Salomon LJ, Bernard JP, Duyme M, Doris B, Mas N and Ville Y. Feasibility and reproducibility of an image-scoring method for quality control of fetal biometry in the second trimester. Ultrasound Obstet Gynecol 2006; 27: 34-40. 